Boštjan BUGARIČ

\title{
Preobrazbe javnega prostora; od modernizma do potrošništva
}

\begin{abstract}
Javni prostor $v$ sodobnem mestu je podvržen spremembam zaradi ekonomskih in političnih interesov in se vse bolj privatizira. Družbene vsebine se $v$ mestu razvijajo na podlagi produkcije kapitala, kar v modernistični formalni zasnovi ni bilo predvideno. Mestno jedro se zaradi neustreznih razvojnih programov in strategij vsebinsko prazni, vsebine pa se selijo $v$ nove oblike urbanistične zasnove - $v$ mesta potrošnje, ki se po navadi razvijajo na mestnih obrobjih. Na podlagi zgodovinskega razvoja mesta Koper se poskuša poiskati ključne trenutke, ki so pripomogli k procesu komercializacije. $V$ obdobju funkcionalizma so poskušali urejati družbeno problematiko mest, ne da bi vzpostavili kritičen odnos do morebitnega vpliva kapitala na javni prostor. Funkcionalizem je historično povezan z demokratično naravnanostjo in socialno angažiranostjo, z razvojem pa je postal vse bolj podrejen kapitalu. Tako je bila ustvarjena idealna osnova za hiperprodukcijo potrošnih mest.
\end{abstract}

\section{Uvod - izginjanje centralnosti v sodobnem mestu}

Javni prostor sodobnih mest se podreja pritiskom kapitala in privatizacije. Zaradi interesa kapitala se preobraža tako družbena kot tudi fizična oblika javnega prostora. Prevlada novih ekonomskih in družbenih vrednot sodobnega načina življenja se manifestira $\mathrm{z}$ izginjanjem javnega prostora v mestih. Preobrazba družbenih mestnih vsebin je rezultat fleksibilnih oblik ekonomske organizacije in hiperprodukcije. S koncentracijo kapitala in globalizacijo se razvoj urbanega območja internacionalizira, globalne vrednote prevladajo nad lokalnimi značilnostmi prostora. Soja (2000) govori o globalizaciji urbanega prostora na lokalni in lokalizaciji na globalni ravni, oboje lahko s seboj prinaša tudi nega-
Public space in the contemporary city is undergoing changes because of economic and political interests and is often falling under private ownership. The programme in the city is developing on the basis of capital production, which was not forseen in the modernistic scheme. Because the developement programme is unsuitable, the city centre is becoming empty and the programme is migrating to a new form of urban structure - the city of consumption - being built in the suburbs. On the basis of analysis of the historical developement of Koper, crucial moments which contributed to the process of comercialization were defined. In the period of functionalism there existed a tendency to regulate social problems in the city, but no critical evaluation of eventual influence of capital on public space was established. Functionalism is historicaly associated with democratic orientation and social engagement, but through the course of history it became increasingly subject to the interest of capital. This provided ideal basis for the hyperproduction of cities of consumption.

tivne posledice. Javni prostor, ki je bil v modernizmu zasnovan na demokratičnem konceptu, se v sodobnem mestu na podlagi globalnih interesov kapitala preoblikuje v internacionaliziran prostor brez lastne identitete. V njem globalne značilnosti prevzemajo prevlado nad lokalnim, ki je premajhno, da bi vzdržalo hudo konkurenco globalnih normativov. Center mesta, v obdobju modernizma nosilec njegove identitete, se v sodobnem mestu preobraža v periferijo, medtem ko se obrobje vse bolj centralizira (Soja, 2000). Sodobna mesta, sicer zasnovana na idealu modernistične tradicije, postajajo zaradi koncentracije centrov moči, (hiper)produkcije in distribucije kapitala okvir produkcije komercialnih družbenih vsebin. Kapitalizem spodbuja nastajanje povsem novih oblik mesta, metropolisa, ki je zadnja stopnja $v$ razvoju urbanega prostora. Tak razvoj nosi s seboj posledice, kot so prenaseljenost, socialna
Modernizem Funkcionalizem Javni prostor Komercializacija Mestno jedro Mesto potrošnje

Modernism Functionalism Public space Comercialization City centre City of consumption 
segregacija in pospešeno onesnaževanje. Metropolis poganja moč kapitalistične ureditve, ki temelji na nenehni akumulaciji kapitala in ne na načelih trajnostnega razvoja.

Proces razraščanja mest je najbolje poznan na primerih velemest $\mathrm{v}$ ZDA, v zadnjem času pa so tudi evropske metropole podvržene t. i. amerikanizaciji prostora, kjer se center spreminja $v$ zapuščeno območje, obrobje pa razvija privlačne komercialne vsebine. Skozi tranzicijo iz industrijske $\mathrm{v}$ postindustrijsko dobo se zlasti historična mestna jedra transformirajo na podlagi dveh razvojnih procesov: na eni strani se kažeta degradacija in zapuščanje prostora zaradi pomanjkanja družbenih vsebin, na drugi pa se z uvajanjem novih oblik organizacije po meri kapitala oblikujejo območja, ki so namenjena izključno za potrebe potrošnje. Mestnim središčem ne uspe konkurirati fleksibilnim in hitro rastočim vsebinam potrošnih mest na obrobju. Proces selitve vsebin iz središča mesta na njegovo obrobje so pospešile cenejša gradnja in možnost manipulacije z zemljišči ter primerna prometna dostopnost s parkirišči, ki s hitrejšo prometno komunikacijo omogoča hitrejšo povezavo. Proces je povzročil decentralizacijo mestnih funkcij, kjer mestno jedro izgublja primarno in osrednjo funkcijo. Mesto ni več funkcionalistično razdeljeno na območje bivanja, dela, rekreacije in območja za preživljanje prostega časa, ampak so nezdružljive vsebine [1] pogosto kombinirane na istem prostoru. Pri takšnem razvoju mesta je ključen interes kapitala, posameznikova volja pa ostaja brez večje vred-

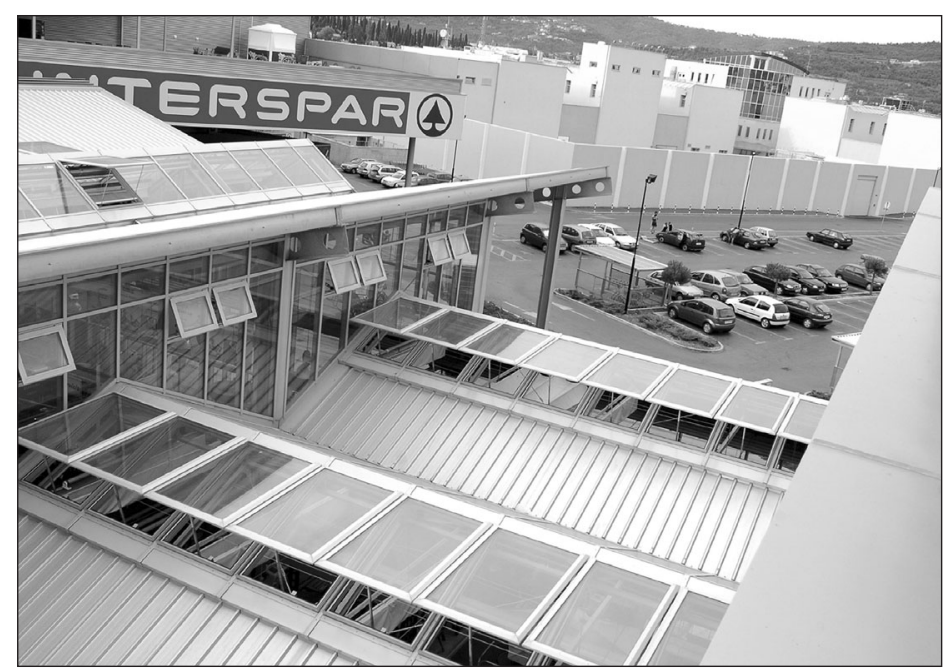

Slika 1: Primer nekompatibilnega vsebinskega povezovanja na robu naravnega rezervata $\vee$ Kopru - nakupovalno središče in mestni zapori si delijo skupno parkirišče. (Foto: Grögl, 2004) nosti. Mestno jedro je precej nezanimivo za gradnjo predvsem zaradi nepopustljivih zahtev spomeniškega varstva in previsokih finančnih zahtev prenove, zaradi zapuščenosti pa se veča tudi socialno razslojevanje prebivalstva. Zlasti pa na proces praznjenja mestnega središča vplivata oddaljenost vsebin in kakovost komunikacij. Razvoj raznovrstnih programov, ki vplivajo na stalno in zanimivo dogajanje na obrobju, veča obisk in uporabo mesta potrošnje, kjer se premišljeno in uspešno razporeja kapital in so vsebine prilagojene uporabniku.

S pridobivanjem lastnih kulturnih, upravnih in celo nastanitvenih funkcij [2] se moč potrošnega mesta povečuje. Kopičenje kapitala se $z$ različnimi simulacijami kaže v fizični strukturi, ki posnema program mestnih jeder. Skozi mesta potrošnje vstopa sodoben potrošnik v hiperrealnost, ki jo je kot koncept simulakrov napovedal že Baudrillard (1999). Kopije originalov mesta predstavljajo simulacije mestnih vsebin, ki se na določeni stopnji preoblikujejo v simulakre [3] ali ponaredbe stvari, ki niso nikoli obstajale (Baudrillard, 1999). Simulakri novih družbenih odnosov so mesta potrošnje, ki so usmerjena h kopičenju kapitala. Načelo kopičenja (u)porabnikom ne ponuja trajne zadovoljitve, »saj so možnosti v njihovem svetu neskončne in množice zapeljivih, ponujenih ciljev ni nikdar mogoče izčrpati « (Bauman, 2002, 93). Zaradi privlačnih vsebin in funkcionalnega zadovoljevanja potrošnikovih potreb (vse aktivnosti na enem mestu, neovirana možnost parkiranja, cenovno ugodnejša ponudba izdelkov) se (u)porabnik raje odloča za obisk mesta potrošnje. A med stalnimi napadi vizualnih dražljajev reklam se izgublja objektivna presoja realnega stanja in zamegljuje privatizacija javnega prostora.

De Cauter (1998) pravi, da interes kapitala pogojuje razvoj sistema organizacije prostora $v$ smislu prevladovanja centralnosti nad periferijo. Model razvoja temelji na disneyfikaciji centra mesta in bronxifikaciji mestnega obrobja. Oblikujejo se dva pola mesta, ki se razvijata povsem avtonomno, ter povsem nove socialne strukture uporabnikov in prebivalcev. Akterji mesta postajajo marionete ekonomskih interesov peščice bogatih, ki s svojimi odločitvami uravnavajo pretok večine kapitala in s tem usmerjajo tudi razvoj javnega prostora. 


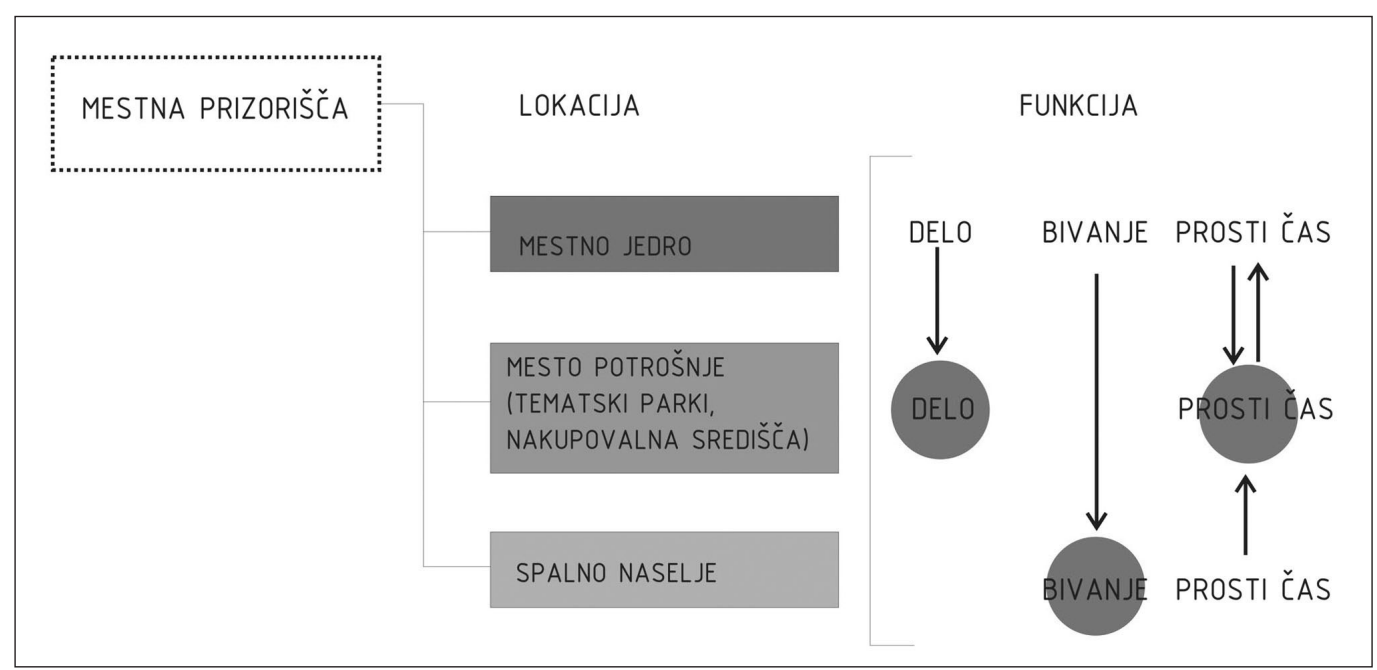

Slika 2: Mestna prizorišča se oblikujejo $v$ različnih mestnih predelih na podlagi delitve funkcij (Vir: Bugarič, 2006)

Zaradi rasti mesta proti zaledju se izoblikujejo samozadostni (sub) lokalni centri, mestno jedro pa zato izgublja vse več družbenih vsebin. Identiteta mesta se prenaša na mestne predele, ki so zanimivejši in omogočajo večji obisk ter nenehno dogajanje. Mestna prizorišča ${ }^{[4]}$ se tako iz mestnega jedra prenašajo v mesto potrošnje, kjer se razvijajo tudi nekatere kulturne, izobraževalne in upravne funkcije novega mesta. V mestu potrošnje se z dodajanjem zabaviščih in upravnih dejavnosti oblikuje samozadostno središče, ki pa ga najbolj zapolnjujejo komercialne vsebine. Zaradi večje privlačnosti, nenehnega dogajanja, večje medijske pozornosti in oglaševanja so prizorišča mesta potrošnje bolj obiskana kot tista v mestnem jedru. Stalen priliv kapitala omogoča mestu potrošnje samoorganizacijo in vzdrževanje prepleta posameznih funkcij, ki jih je prvotno opravljalo mestno jedro (uprava, kultura, zabava).

\section{Od modernistične tradicije do privatizacije javnega}

Modernistični arhitekturni pristop k organiziranosti prostora je sledil duhu modernega načina življenja v skladu s funkcionalističnim motom »Form Follows Function« [5]. V tem kontekstu se je javni prostor oblikoval v organiziran sistem, kjer je razvoj potekal na podlagi funkcionalističnih pravil. Podobno totalitarno ureditev znotraj oblikovanja javnega prostora in njegovega urbanističnega urejanja se sicer zaznava že v predhodnem obdobju naselitve proletariata $\mathrm{v}$ mesto. Urbanizem kot aplikativna znanost meščanskega razreda je bil namreč uporabljen kot orodje za discipliniranje anonimnega delavskega razreda. Z obvladovanjem prostora na načelih ekonomskih zakonitosti sta bili za kratek čas omejeni kaotična rast in ekspanzija mest. Sposobnost obvladovanja posameznika s sistemom ureditve modernističnega mesta je zametek ekonomskega obvladovanja javnega prostora, ki ga vse močneje izkušamo. Nadzorovanje posameznika, ki je bil včasih nadziran le v delovnem času in prostoru, se zdaj prenaša na celoten javni prostor in poteka nenehno. Predvsem skrbno pa je nadzorovan prostor nakupovalnih središč.

S privatizacijo javnega prostora se onemogoča možnost demokratičnega odločanja o prostorskih problemih. Javni prostor v osnovi ni več namenjen javnosti, kar vodi v preobrazbo krajev v nekraje. Kraji so območja v mestu, ki izražajo identifikacijske potrebe. Po Augéju (1999) se s kraji izražajo odnosi identitete, relacij in zgodovinskih predpostavk. Obiskovalec ali uporabnik lahko v kraju prepoznava določene segmente lastne zgodovine, odkriva vezi, ki ga povezujejo $\mathrm{z}$ drugimi pripadniki istega kraja, ter navezuje socialne stike. V nasprotju s krajem je nekraj brez simbolnih izrazov, ki odsevajo identiteto, razmerja ali zgodovinske predispozicije. Bauman (2002) trdi, da zavzemajo nekraji vse večji delež fizičnega prostora, čeprav so namenjeni zgolj prečkanju in jih po navadi hitro zapustimo. Najbolj vsakdanji primeri nekrajev so nakupovalna središča, 
letališča, avtoceste, anonimne hotelske sobe, javni komunikacijski terminali itd. V nekrajih se meja med javnim in zasebnim briše, javni prostor postaja zasebni prostor potrošnje. V nasprotju z iniciativnim individualizmom v ideologiji zgodnjega kapitalizma je sodobni potrošniški individualizem pasiven, zato je pasiven tudi sodobni javni prostor (Auge, 1999).

Le Corbusierjeva definicija arhitekta kot socialnega reformatorja je vsebovala domnevo, da bo kapital pripomogel k množični proizvodnji hiš in s tem uredil problem neurejenih bivalnih razmer med socialno šibkim prebivalstvom. Pri tem ni bilo kritične presoje potencialne vloge kapitala, ki lahko s svojo fleksibilno vsebinsko ekspanzijo popolnoma prevzame prevlado nad modernističnimi okvirji prostora [6]. Strokovna plat urbanega planiranja ima $\mathrm{v}$ takem primeru zvezane roke, kar pripomore $\mathrm{k}$ neuravnoteženemu in nenadzorovanemu razvoju mesta. Funkcionalistični moto »Form Follows Function« se tako v postmodernizmu izrazi kot »Form Follows Finance ${ }^{[7]}$ - javni prostor postane bojišče kapitala. Tako se v sodobnem mestu organizacija javnega prostora izvaja na ravni ekonomskih in političnih odločitev, neodvisno od urbanistične regulative. Organizacija aktivnosti v javnem prostoru se manifestira kot del serijske produkcije banalnega. Debord (1999) celo definira spektakel kot glavni smisel delovanja družbenoekonomske ureditve in tako narekuje urnik celotnega dogajanja v mestu.

Posameznik je v sodobnem mestu ujet $\mathrm{v}$ pasivnost kapitalističnega individualizma, kjer je, zaslepljen s potrošniškimi utopijami, nezmožen objektivno presoditi, kaj je pomembno. Jameson (2001) poudarja, da razvoj potrošniškega kapitalizma konstituira najčistejšo obliko kapitala, kar se jih je doslej pojavilo, in z njo kolonizira nova območja. Javni prostor se v službi porabe - osnovne aktivnosti družbenega življenja - pretvarja $\mathrm{v}$ nadzorovan prostor. »Mesto postaja okvir privatne prodaje in javni prostor je integralni del te privatizacije « (Madanipour, 2003, 238). Urbanistična regulativa ne zmore obvladovati in usmerjati razvoja po potrebah javnosti ali stroke, ker je ujeta v interese investicij kapitala. Urbano planiranje se namreč pogosto podreja interesom investitorjev. Reforme, ki stroko povezujejo izključno z gospodarstvom, ji še dodatno odvzemajo av- tonomijo. Stroka se z gospodarstvom povezuje tako, da je marsikdaj vprašljivo in $\mathrm{v}$ marsikaterem pogledu negativno. Odvzeta ji je celo možnost kritike neupravičenih posegov kapitala v prostor. Produkti planiranja pod pritiskom kapitala narekujejo posebne oblike reprezentacije javnega prostora, v katerem se načrtno vodi tudi družbene vsebine. Po namembnosti se javni prostori ločujejo na tiste za višje in tiste za nižje družbene sloje. Tipi dogodkov v teh območjih so načrtovani in jasno določeni. Javni prostori spreminjajo svojo namembnost in postajajo lastnina zasebnih podjetij bolj kot prave javne površine. Tako organizirani prostori so skrbno nadzorovani, mesto postaja scenografija (za predstavo) kapitala, kjer se dogajanje zrcali v očesu nevidne kamere.

\section{Izginjanje javnega človeka}

Turistifikacija in sitizacija sta procesa, ki pomembno zaznamujeta družbene vsebine javnega prostora. V mesto uvajata dve obliki organizacije kapitala, ki onemogočata razvoj raznovrstnosti družbenih vsebin in podpirata le določen tip aktivnosti. Čezmerno razvijanje turističnih aktivnosti pomeni vsebinsko degradacijo za prebivalce takšnega območja. Vsekakor velja, da se s pomočjo turističnih aktivnosti pospeši revitalizacijo zapuščenih mestnih predelov, vendar se lahko prostor zaradi precejšnje vključenosti komercialnih akterjev preobraža le v namene turistične ponudbe (Hočevar, 1998). S turizmom se poskuša čim hitreje pritegniti v mesto velik priliv kapitala ne glede na potrebe prebivalcev. Graafland (2000) navaja, da postaja turistična industrija najpomembnejši vir dobička, kar prinaša veliko negativnih dejavnikov za prebivalce mest $\mathrm{z}$ naraščajočim deležem turističnih vsebin. »Turistifikacija je posebno značilna za slovenska mediteranska mesta. Prostorske danosti so izkoriščene v namene turizma, kar delno spodbuja razvoj območja. Problem se pojavi, ko postanejo turistične vsebine najpomembnejša panoga $\mathrm{v}$ mestu. To s seboj prinaša tudi negativne dejavnike, kot so izguba identitete zaradi pomanjkanja deleža avtohtonih prebivalcev, problem razvoja prometne infrastrukture in onesnaženje okolja. Kakovost življenja $\mathrm{v}$ mestu $\mathrm{z}$ intenzivno turistifikacijo se občutno zmanjšuje.« (Bugarič, 2006, 62). 
Drug primer organizacije kapitala znotraj določenega mestnega predela je proces sitizacije oziroma poslovne revitalizacije, v katerem se mestno jedro spreminja $\mathrm{v}$ poslovno središče. Proces sitizacije uvaja enolične poslovne aktivnosti in s tem zmanjšuje privlačnost lokacij za druge dejavnosti, objekti postajajo nedostopni zaradi zviševanja najemnin, javni prostori se (pol)privatizirajo in praznijo v večernih urah, ko se delavnik konča (Hočevar, 1998). Značilnost takšnih mestnih predelov je enoličen utrip, ki se konča ob koncu delovnih ur. Iz mestnega jedra se s procesom sitizacije izrinja bivalna funkcija, namembnost stanovanj se spreminja $\mathrm{v}$ pisarne ali prostore za upravne dejavnosti. Taka območja nastajajo zaradi pomanjkanja in slabitve performativnih in reprezentativnih funkcij osrednjih mestnih prostorov, ugotavlja Hočevar (2002) in dodaja, da s tem izginja tip javnega človeka, kar je tudi logična posledica izginjanja javnega prostora.

Z izjemno sposobnostjo prilagajanja se kapitalske vsebine zlahka umestijo $\mathrm{v}$ različne okoliščine mesta in ne glede na družbene potrebe ustvarjajo simulirana območja, umetna okolja, kjer se zmanjša komunikacija z zunanjostjo (De Cauter, 1998). Tako se ustvarja poseben razvojni sistem, ki ustvarja lastne blagovne znamke, ne upoštevajoč značilnosti prostora ali njegovih uporabnikov.

\section{Historično prek modernega $\mathrm{v}$ potrošno}

Na primeru razvoja mesta Koper lahko pokažemo ključna dejstva, ki nakazujejo privatizacijo javnega prostora. Modernizem, ki je poskušal definirati novo fizično strukturo za novo družbeno strukturo v mestu (proletariat) in končati buržoazno tradicijo srednjeveških palač, ostaja zdaj zgolj kot privid družbene enakosti. Pri razvoju mesta Koper je močno čutiti vpliv modernizma, vendar s trdnimi ideološkimi konotacijami. Socialistična ureditev SFRJ je determinirala tudi prostorski razvoj, ki je bil predvsem na urbanistični ravni ideološki aparat urejanja družbenih odnosov v mestu. Po tem se razlikuje od klasičnega funkcionalizma po Corbusierju, ki je odpiral nastavke za razvoj mesta s pomočjo novega kapitala.

Vrnimo se na konkreten primer Mihevčevega urejanja mesta. Predlog asanacije starega mestnega jedra je v letu 1967 predvidel konkretno in temeljito rušenje starih objektov ne glede na njihovo spomeniško vrednost. Posege je opravičevalo dejstvo, da moderno mesto potrebuje novo stanovanjsko zazidavo za sodobnega človeka. V obdobju funkcionalizma so bili načrtovani drastični posegi v historično jedro, ki pa niso bili nikoli izvedeni v celoti. Predvidena sta bila rušenje stanovanjske zazidave na obodu starega mestnega jedra in gradnja stanovanjskih nebotičnikov za bivalne potrebe delavske populacije. Prve Mihevčeve stanovanjske stolpnice v Kopru so leta 1958 posegle v staro mestno silhueto, saj so konkurirale dominanti cerkvenega zvonika in tako sprožile ostre kritike predvsem s spomeniškovarstvenega stališča. Gradnja stolpnic naj bi izkoristila trdno strukturo tal, pridobili bi več prostora za zelene površine, ki

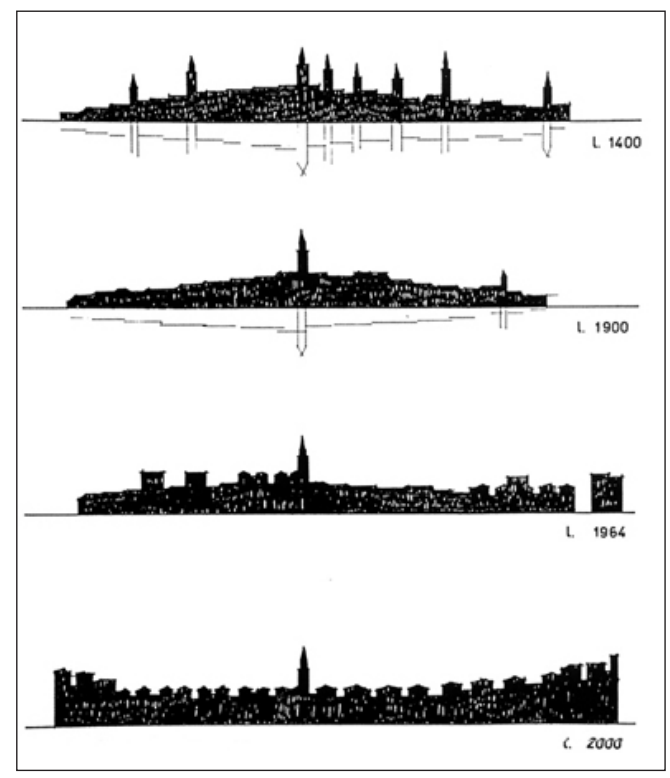

Slika 3: Silhueta mestnega jedra Kopra v različnih obdobjih. (Vir: Guček, 2000)

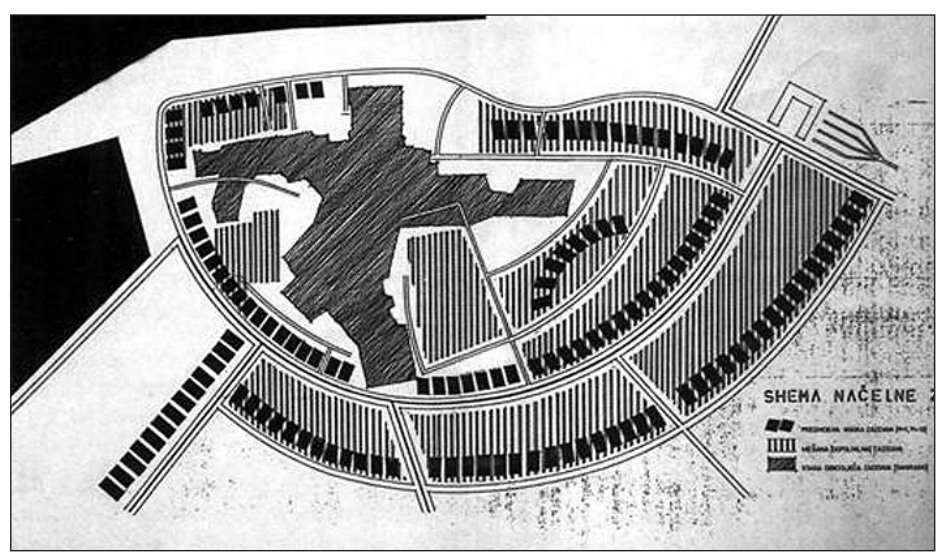

Slika 4: Predlog asanacije mestnega jedra Kopra s shemo nove zazidave. (Vir: Guček, 2000) 
bi dajale mestu zračnost in svetlobo. Po urbanističnem načrtu naj bi stolpnice obkrožale celotno mestno jedro (Koselj, 1995). Struktura otoka je narekovala zazidavo večjih palač v osrednjem delu mestnega jedra, proti obodu pa se je zaradi manjše nosilnosti terena razvila stanovanjska struktura. Projekt stolpnic je bolj kot $\mathrm{k}$ novi funkciji prispeval $\mathrm{k}$ novi ideologiji mesta, za delavce je bila izoblikovana nova stanovanjska oblika - nebotičnik. Projekt gradnje nebotičnikov se je začel s prvim Mihevčevim objektom, ki stoji na Nazorjevem trgu. Zaradi neustreznosti predloga rušitev je bil projekt opuščen in v letu 1967 sta konservatorja Murko in Rotar pripravila nov predlog prenove mestnega jedra ${ }^{[8]}$.

Sprememba demografske strukture prebivalcev v mestnem jedru Kopra je sledila fizičnim okvirjem funkcionalističnega mesta. Zaradi preseljevanja je postala struktura prebivalcev $\mathrm{v}$ mestnem jedru enolična in manj zahtevna glede spremljevalnega (kulturnega, športnega, izobraževalnega) programa. To je glavni vzrok za opuščanje programske

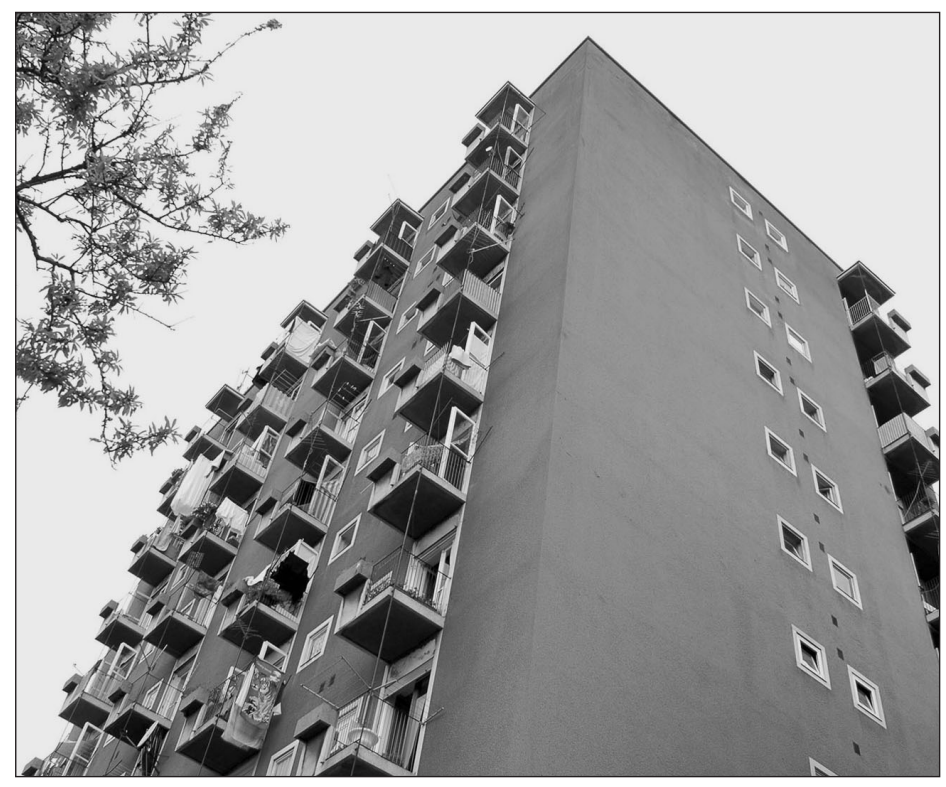

Slika 5: Mihevčeva stolpnica ruši razmerja v starem mestnem jedru. (Foto: Grögl, 2004) pestrosti in dejavnosti v mestnem jedru. Zaradi nenehnih migracij se je onemogočil razvoj kolektivne identitete, ki se navadno izoblikuje v krajih s stalnim prebivalstvom.

Podoba mestnega jedra zdaj izpričuje neuravnoteženost delovanja mestnih akterjev. V Kopru se na sorazmerno strnjenem območju srečujejo med seboj nezdružljivi sistemi mestno jedro, mesto potrošnje in industrijsko območje pristanišča. Samo mestno jedro je v slabem fizičnem stanju, saj je brez ustrezne infrastrukture, kaže pa se tudi pomanjkanje družbenih vsebin. Velik problem je vprašanje lastništva objektov, zaradi česar je dokumentacija o njih neurejena, objekti pa slabo vzdrževani in prazni. Prevladujoča upravna dejavnost, ki je posledica začetne sitizacije in birokratizacije mestnega jedra, mestno jedro aktivira le med uradnimi urami. Prostorski razvojni plan se podreja interesu kapitala in političnih odločitev, razmerja med gospodarskimi akterji in civilno družbo so neurejena. Projekti družbenega pomena dobivajo fasade političnih odločitev [9], urejanje javnega prostora je podvrženo postopni privatizaciji. Namesto Mihevčevega ideološkega projekta obzidja nebotičnikov prekriva danes pogled na veduto koprskega mestnega jedra podoba nakupovalnih središč in pristaniške infrastrukture. Kapitalistični hiperurbanizem ureja načrtovanje brez načrtov, kjer je kapital glavni generator družbenega dogajanja. To vključuje tudi dogajanje v mestu, kjer se utrip s senčnih kamnitih mediteranskih ulic seli v neonske prostore nakupovalnih središč na mestnem obrobju.

V modernizmu je forma prevladala nad dolgoročnim vsebinskim razvojem mesta. Zaradi poudarjanja forme je modernizem ustvaril idealno podlago za razvoj hitro spreminjajočih se oblik mesta potrošnje. Te se razraščajo zaradi prilagodljivosti vsebin kapitala in ne izbirajo prostorskih usmeritev. Tako lahko hitro prerastejo tudi vse urbanistične normative. Kot je vidno na koprskem prime-

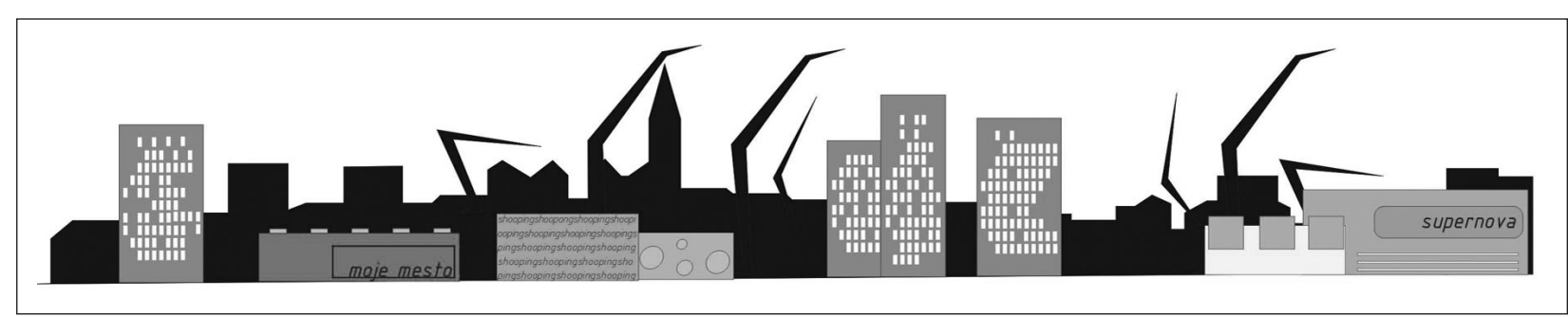

Slika 6: Simulacija koprske silhuete danes na podlagi razvoja mesta potrošnje. (Vir: avtor) 
ru, je odločilno vlogo pri omejevanju izvajanja ideološke modernistične zasnove igrala stroka. Ekonomski hiperurbanizem ustvarja skrbno nadzorovane totalitarne prostore, kjer se posameznik izgubi v navidezni resničnosti javnega prostora. Produkcija takšnih prostorov se prožno prilagaja vsakokratnim ekonomskim potrebam množične proizvodnje, tradicionalno togi urbanizem pa pri pomembnem segmentu načrtovanja mesta vse bolj izgublja moč odločanja.

Dr. Boštjan Bugarič, univ. dipl. inž. arh. e-pošta: bostjan.bugaric@guest.arnes.si

\section{Opombe}

[1] Značilen primer kombiniranja nezdružljivih vsebin zaradi kapitalskega interesa je mesto potrošnje $v$ Kopru, ki se razvija na robu zavarovanega območja Škocjanskega zatoka. Nakupovalno središče Supernova si celo deli parkirišče z mestnimi zapori.

[2] Poleg trgovskih vsebin kombinirajo nekatera nakupovalna središča v ZDA med seboj mestotvorne aktivnosti kot gledališče, cerkev ali hotel (Strong, 2003).

[3] Simulaker je posnetek, izmišljeno stanje (dejanje), ki je videti kot resnično (Baudrillard, 1999).

[4] Hočevar (2000) definira urbana prizorišča kot kraje z namensko in nenamensko konstruiranimi dogodki $\checkmark$ odprtih ali zaprtih javnih prostorih ter $v$ zasebnih prostorih z javnim dostopom. Vanje umeščene začasne ali trajne prostorske situacijske postavitve večajo privlačnost in spodbujajo obravnavo problematike območja. Hočevar (2000) opisuje urbana prizorišča kot celoto funkcijskih, simbolno-pomenskih in formalno-oblikovnih razsežnosti performativnega delovanja ter določen način družbene (re)produkcije prostorov $v$ mestu.

[5] Forma sledi funkciji

[6] Modernistično arhitekturo poslovnih in upravnih objektov, ki se je v petdesetih letih razvila na območju ZDA, so finančno podprle velike korporacije. So okvir za kapitalistično delovanje, izgublja pa se družbeno-socialna naravnanost.

[7] Forma sledi financam

[8] Istega leta je Zavod za spomeniško varstvo SRS izdelal spomeniškovarstveni elaborat inventarizacije in kategorizacije kulturnih spomenikov $v$ mestnem jedru Kopra. Elaborat so pripravili dr. Curk, dr. Komelj, dr. Sedej, Šumi in dr. Zadnikar. Inventariziran je bil stavbni fond mestnega jedra, s topografsko obdelavo pomembnih spomenikov in najpomembnejših mestnih ambientov. Elaborat je obdelal območje historičnega mestnega jedra Kopra in takrat še nastajajoče spalno naselje Semedela.

[9] Fasada nove osnovne šole na Bonifiki, ki je nadomestila modernistično Mihevčevo, nosi politični manifest. Na sprednji fasadi se z odstotnim deležem in besedo hvala trenutna oblast zahvaljuje volivcem za podporo. Družbena zgradba postane nosilec politične volje trenutne oblasti.

\section{Viri in literatura}

Augé, M. (1999) Novi svetovi, Mestomorfoze. Sorosov center za sodobne umetnosti, Ljubljana.

Bauman, Z. (2002) Tekoča moderna. Rdeča zbirka, Ljubljana.

Baudrillard, J. (1999) Simulaker in simulacija; Popoln Zločin. Študentska založba, Knjižna zbirka Koda, Ljubljana.

Bugarič, B. (2006) Univerza in mesto; univerzitetne vsebine kot generator družbenega dogajanja (doktorska disertacija). Fakulteta za arhitekturo, Univerza v Ljubljani, Ljubljana.

Debord, G. (1999) Družba spektakla; Komentarji k Družbi spektakla; Panegirik. ŠOU, Študentska založba, Knjižna zbirka Koda, Ljubljana.

De Cauter, L. (1998) The Capsular Civilization; The city in the Age og Transcendental Capitalism.Nai Publishers, Rotterdam.

Graafland, A. (2000) The Socius of Architecture; Amsterdam. Tokyo. New York. 010 Publishers, Rotterdam.

Guček, M. (2000) Anonimna arhitektura v prenovi Kopra. Knjižnica Anales Majora, Zgodovinsko društvo za južno primorsko, Znanstveno-raziskovalno središče RS Koper.

Hočevar, M. (2002) Ljubliana: konec ali začetek urbanosti?. Sociološke podobe Ljubljane, Fakulteta za družbene vede, Ljubljana.

Hočevar, M. (2000) Novi urbani trendi: prizorišča v mestih - omrežja med mesti. Fakulteta za družbene vede, Ljubljana.

Hočevar, M., (1998) Analiza revitalizacijske problematike koprskega mestnega jedra; fizični prostor in družbene vsebine. Annales, 12/1998, str. 79-94.

Jameson, F. (2001) Postmodernizem. Društvo za teoretsko psihoanalizo, zbirka Analekta, Ljubljana.

Koselj, N. (1997) Arhitektura 60. let v Sloveniji; kontinuiteta ideja. $A B$ - posebna izdaja, letnik XXV.

Madanipour, A. (2003) Public and private spaces of the city. Routledge, London.

Soja, E. (2000) Postmetropolis: critical studies of cities and regions. Blackwell, Oxford.

Strong, G. (2003) Shoppology: The Science of Shopping (dokumentarna oddaja). Velika Britanija, BBC. 